\title{
AGRI-FOOD HAZARDS
}

\section{Systemic vulnerability \\ Land Use Policy 87, 104041 (2019).}

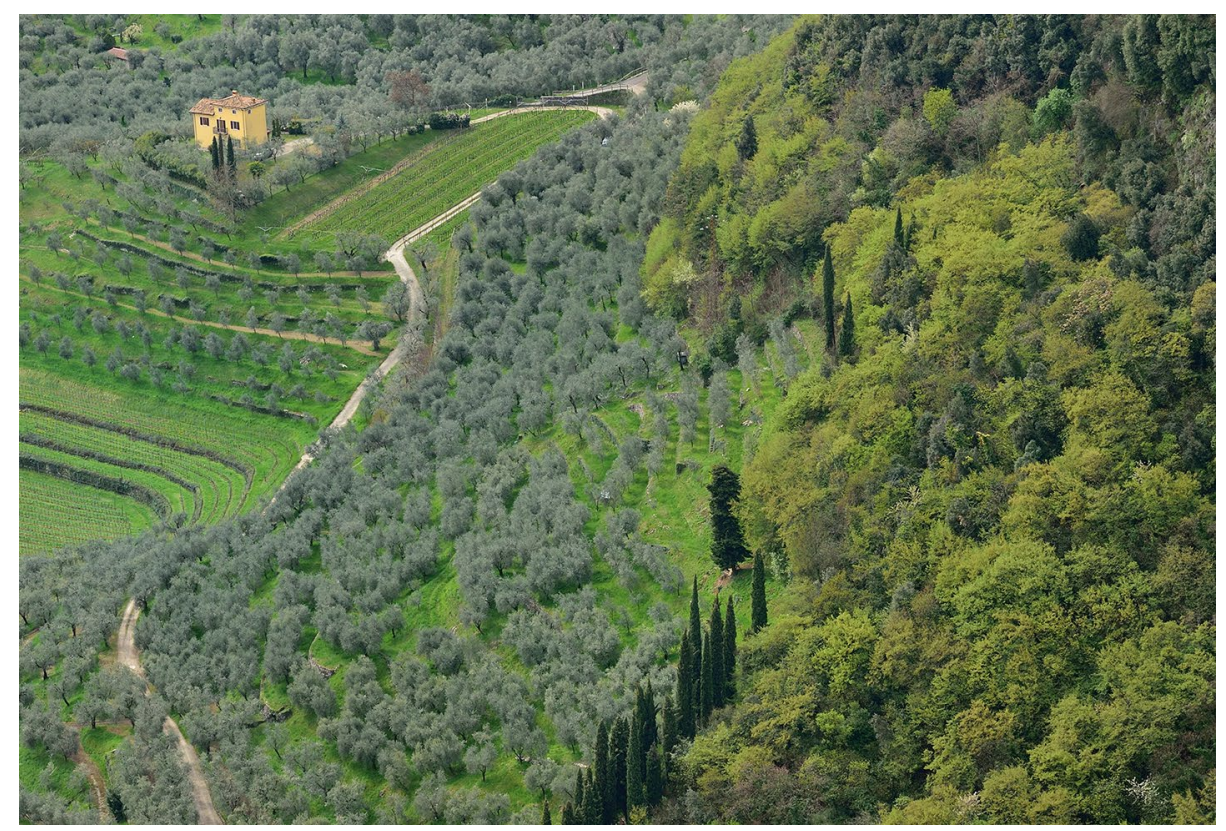

Credit: DEA / ALBERT CEOLAN / Contributor / De Agostini / Getty

Studies on disaster risks have been surging in recent years, especially with the United Nation's Sendai Framework for reducing such risks by 2030 . However, much of the research has focused either on already vulnerable regions or on cities and their population and economic activity, leaving agricultural regions and production somewhat neglected.

Francesco Pagliacci, at the Università degli Studi di Modena e Reggio Emilia, created a risk assessment case study for Italian agri-food production under the premise that 'risk' is a function of hazards, exposure and vulnerability to natural disasters. Quantifying indicators for these functions at the municipality level across the country, Pagliacci was able to develop multiple maps for the type of risk posed by potential disasters - such as floods or landslides - and determined that some of the areas with the highest exposure were also characterized by agricultural and food production. Beyond the geophysical division of disaster likelihood is the divide regarding which regions would be more vulnerable based on socio-economic preparedness and response. A shock to agri-food systems, even if localized to those regions and not cities, could affect an entire country.

\section{Ryan Scarrow}

Published online: 9 September 2019 https://doi.org/10.1038/s41477-019-0518-5 